\title{
Effects of different decorporating agents on the whole-body retention of radioisotopes
}

\author{
GACHÁLYI András, GYULAI Gábor ${ }^{1}$
}

\begin{abstract}
Internal contamination of people (persons) working in the nuclear industry and laboratories or living near such establishments may occur as a result of single or repeated exposures to radionuclides. Some of the population that might ingest ra-dionuclides could also be expected to receive substantial doses of external (mainly gamma-rays and/or neutrons) radiation.

Among the fission products forming in nuclear reactions are elements such as strontium, niobium, caesium, rare earth elements and plutonium. These play an important role when they are released into the environment and are also the focal point of radiation protection.

The authors investigated the effectiveness of some important decorporating com-pounds in the case of internal contamination with radionuclides (cesium, strontium and cerium) in animal experiments.
\end{abstract}

\section{Introduction}

In recent years, as a result of urbanization and the development of the industry there is greater need to be prepared for more severe contamination of the environment. Emerging environ- mental contaminants (radioactive and/or toxic metals, hazardous waste, etc.), either directly or indirectly (e.g. through the food chain), pose a potential danger to people performing any kinds of tasks in these areas, as well as the local population.

All around the word there is still a large number of nuclear power plants, training and research reactors which can be potential sources of contamination during every day work (i.e. fuel substitution, waste transport and storage, filtration) and/or in case of malfunction such as the failure of the cooling systems or reactor accidents. Thus, the reactor staff and rescue workers are directly exposed to a combined effect of the external radiation (beta-, gamma-), and the internal radionuclide load coming from possible inhalation or swallowing substances containing radionuclides.

In recent years, terrorist acts (e.g. "dirty bombs") clearly demonstrated that the world should be prepared for unexpected and seemingly unavoidable events.

We have investigated the toxicological properties, deposition and elimination characteris- tics of these radionuclides (for example: strontium, caesium, cerium) in animal experiments.

1 gabor.gy@citromail.hu 


\section{Material and methods}

Experiments were performed on white female rats of the strain CFY (origin HRC England

Laboratory Animals, bred in Laboratory Animals Institute, Gödöllö, Hungary) weighing

$200 \pm 15 \mathrm{~g}$. The animals were kept in an air-conditioned room and fed granulated chow and tap water ad libitum.

In experiments with pregnant rats, the time of pregnancy was calculated from the second day of mating and eventually corrected on the basis of fetal gain in weight or the time of birth.

The animals were given intraperitoneally (i.p.) and/or by stomach tube (g.t.) a distilled water solution of isotopes (Sr-85-chloride, Cs-134-chloride and Ce-144-chloride) with an activity of $185 \mathrm{kBq}$.

As decorporating compounds, $D K-1$ (DTPA, Na2Ca - diethylenetriaminepenta-acetic acid, MEDITOP, Hungary), $D K-2$ (PB, Prussian blue, MEDITOP, Hungary) and $D K-3$ (nat- ural high molecular weight polysaccharide, MEDITOP, Hungary) were administered.

The initial body burdens of injected isotopes (IBB) were determined by a whole-body $\gamma$-ray counter 30 minutes after isotope administration. Values of daily measurements were compared to a standard solution prepared for the stock solution. Changes in whole-body activity were followed for 20-35 days.

The retention data for each animal were submitted to a computer program. The derived

parameters that provided best fit of the data to the curve described by

$\mathrm{Y}=\mathrm{Ae}^{-0,693 \mathrm{t} / \mathrm{T} 1}+\mathrm{Be}^{-0,693 \mathrm{t} / \mathrm{T} 2}$

equation, where $\mathbf{t}$ is the time in days after exposure, and $T 1$ and $T 2$ are the biological half-times in days. Differences between means were evaluated using Student's $t$ test and were considered significant when the $\mathrm{P}$ values were less than 0.05 .

\section{Results and Discussion}

1.) Mobilization of Cs-134 by DK-2 (Prussian-blue) in normal (non-pregnant) and pregnant rats:

Radio-caesium isotopes (mainly $\mathrm{Cs}-134$ and Cs-137) are considered a major fission product (approx. 6\% are formed) and associated with fallout from nuclear weapons and ra- dioactive waste from nuclear power plants. The absorption from both the GIT (gastrointesti- nal tract) and the lungs are very easy/effective. The cesium compounds can be absorbed into the body within 1 hour after exposition. Caesium — in the living body — behaves similarly to potassium, it is evenly distributing, especially in the muscles build-up. [7]

As the potential risk of exposure exits not only for non-pregnant but pregnant organisms, experiments were initiated to study how pregnancy will influence the retention and transfer of radioactive caesium as well as the efficacy of $D K-2$ (the Prussian-blue was administered by gastric tube or mixed with food) treatments in non-pregnant and pregnant rats exposed (single dose or continuously) to $\mathrm{Cs}-134$ as a chloride.

The whole body retention of Cs-134 administered by g.t. (single dose) to non-pregnant and pregnant animals and the efficacy of applied treatments is shown in Figure 1, Figure 2 and Figure 3 shows the Cs-134 intake per body gram of new-born rats. (The all figures, which are based on their own experiments created by the authors.) 
It can be stated that the feeding of animals with food containing $1 \%$ DK-2 and their si- multaneous exposition to Cs-134 significantly reduced the body burden by 5-20\% of control values both in non-pregnant and pregnant rats.

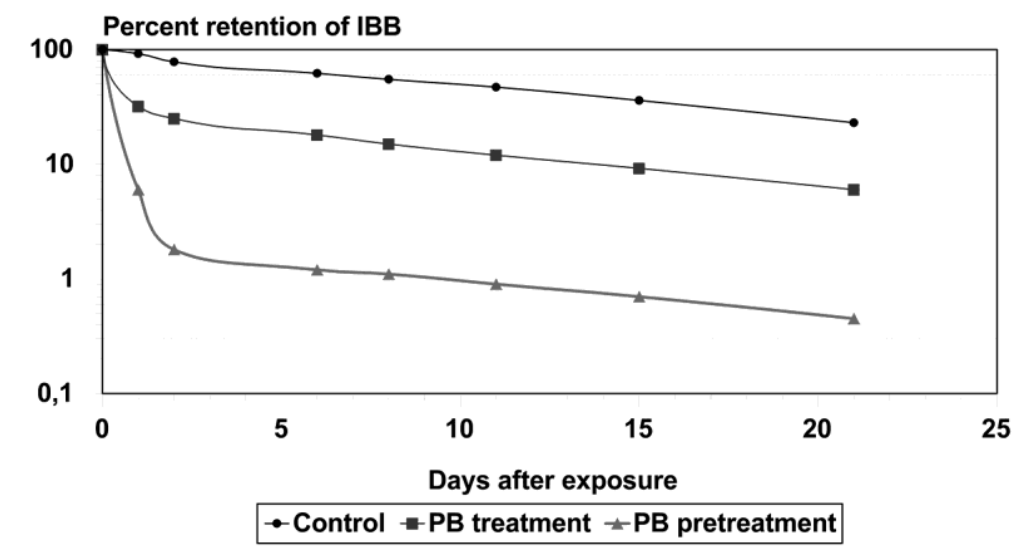

Figure 1. Effect of DK2 on the whole body retention of Cs-134 in non-pregnant rats

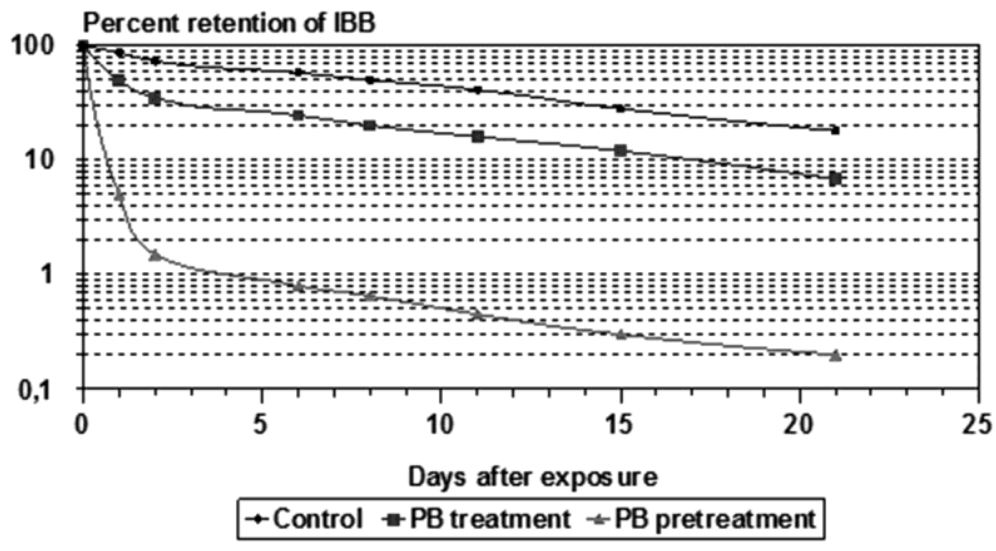

Figure 2. Effect of DK2 on the whole body retention of $C s-134$ in pregnant rats 


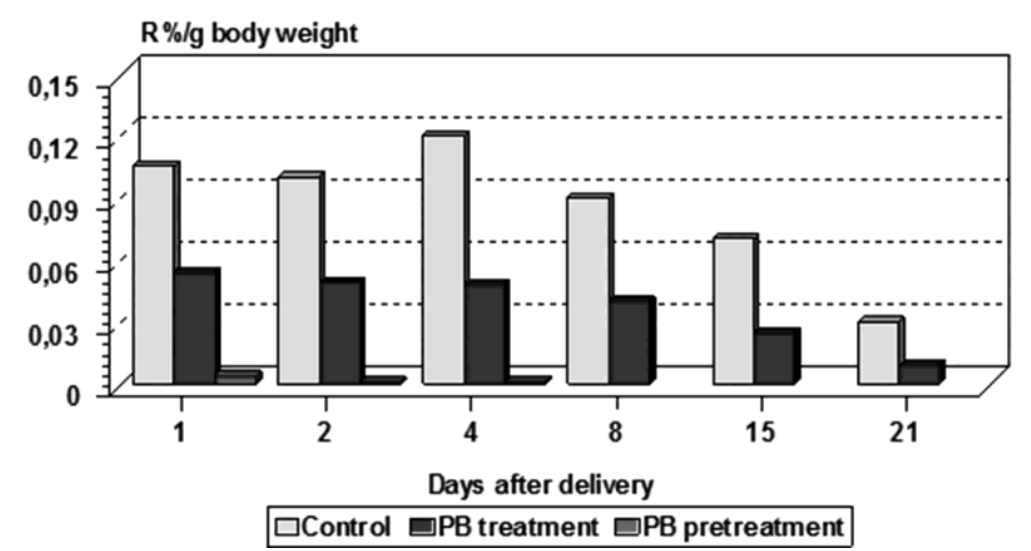

Figure 3. Cs-134 intake/gram body weight of new-born rats as a percent of the mother's initial body burden $(I B B)$

The efficacy of the whole-body retention of Cs-134 through applied DK-2 treatment on normal rats (exposed to Cs-134 contamination continuously in drinking water) is shown in Figure 4. Figure 5 and respectively Figure 6 show the Cs-134 intake per body gram of new-born rats.

The DK-2 treatment just after exposure (the Cs-134 is administered continuously through giving drinking water to adult rats) reduced the body burden by $50-70 \%$ both in non-pregnant and pregnant rats. Three-day pre-treatment eliminated an additional $30 \%$ of the caesium contamination. In new-borns with mothers treated with a single dose of DK-2 the content of the body was 50\% less than that of the controls. Practically no Cs was found in new-borns when their mothers were pre-treated with food containing DK-2.

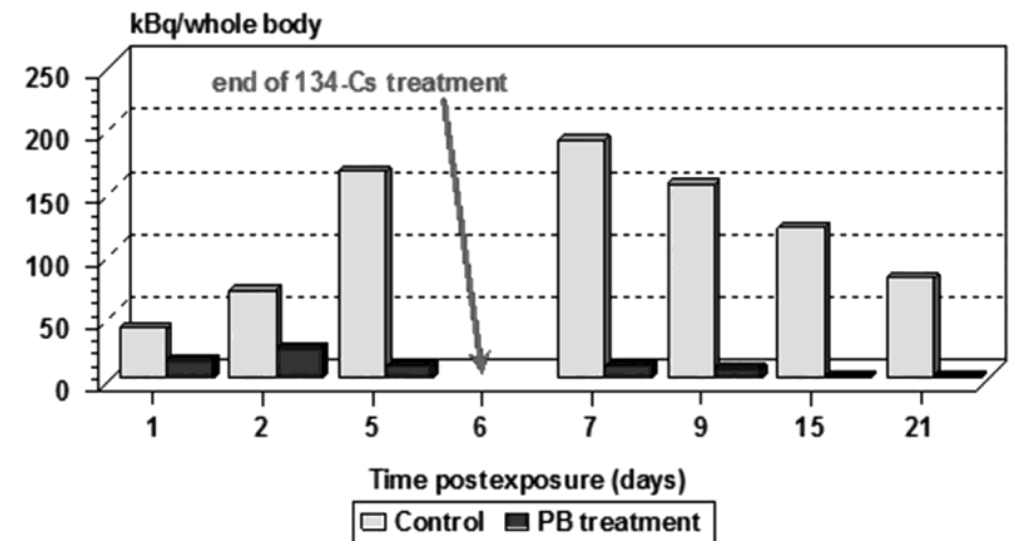

Figure 4. Effect of DK2 on the uptake and whole body retention of Cs in non-pregnant rats exposed to $C s-134$ by contaminated drinking water 


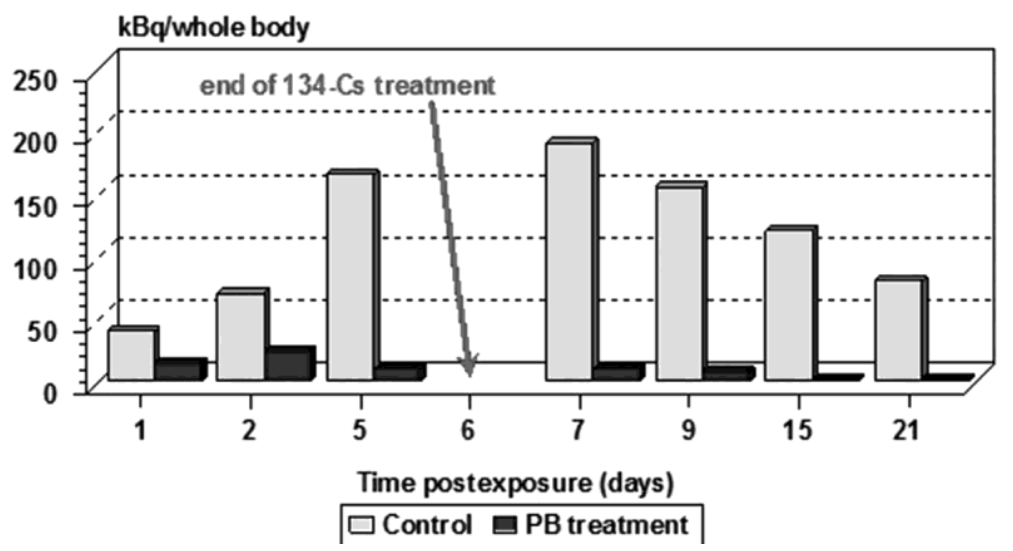

Figure 5. Effect of DK2 on the uptake and whole body retention of Cs in pregnant rats exposed to Cs134 by contaminated drinking water

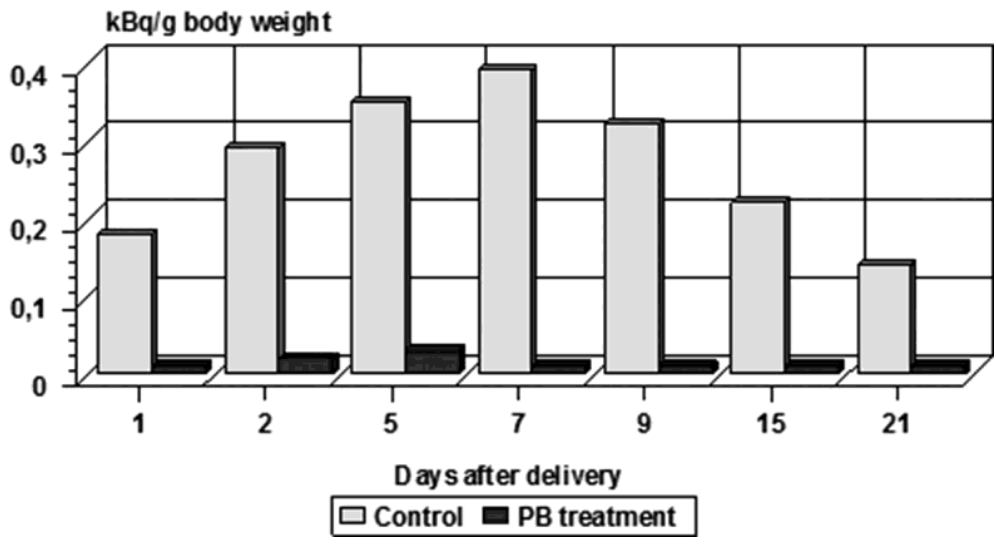

Figure 6. Cs-134 intake of new-born rats

2.) Mobilization of $\mathrm{Sr}-85$ by $\mathrm{DK}-3$ in non-pregnant and pregnant rats

Strontium isotopes of fission products are ones of the most dangerous (physiologically) ele- ments because - strontium as a member of alkaline earth metals - can easily substitute calcium in biological systems. During a nuclear explosion many strontium ( $\mathrm{Sr}-85, \mathrm{Sr}-89, \mathrm{Sr}-90)$ iso- topes are created which are dangerous due to their determined first physical half-life.

[1] [4] [5] These strontium compounds are relatively well soluble in water and body fluids, so that they can easily be absorbed.

The absorbed compounds quickly disappear from the circulation and appear mostly in bones in the form of deposition. These compounds get involved in the metabolic process of the bone, become embedded in the bone matrix, and then very slowly, during almost 20 years of effective half-life the kidneys slowly excrete the wastes through urine.

The mobilization of radioactive strontium has not been properly solved, it seemed of interest to study the efficacy of the DK-3 (natural high molecular weight polysaccharide) compound in strontium decorporation. 
The whole-body retention of $\mathrm{Sr}-85$ administered by stomach tube to adult animals and

the efficacy of applied treatment are shown in the Figure 7 and Figure 8 respectively. Figure

9 shows the $\mathrm{Sr}-85$ intake in the different stages of pregnancy as well as in new-born rats.

It can be established that $\mathrm{Sr}-85$ can beneficially be mobilised with administration of $\mathrm{DK}-3$. The retained amount of $\mathrm{Sr}-85$ in the animals decreased by about $50-70 \%$. In case of newborn rats the applied treatments reduced the whole body burden of the foetuses in the treated group by $20-40 \%$ of control values.

\section{Perœnt retention of IBB}

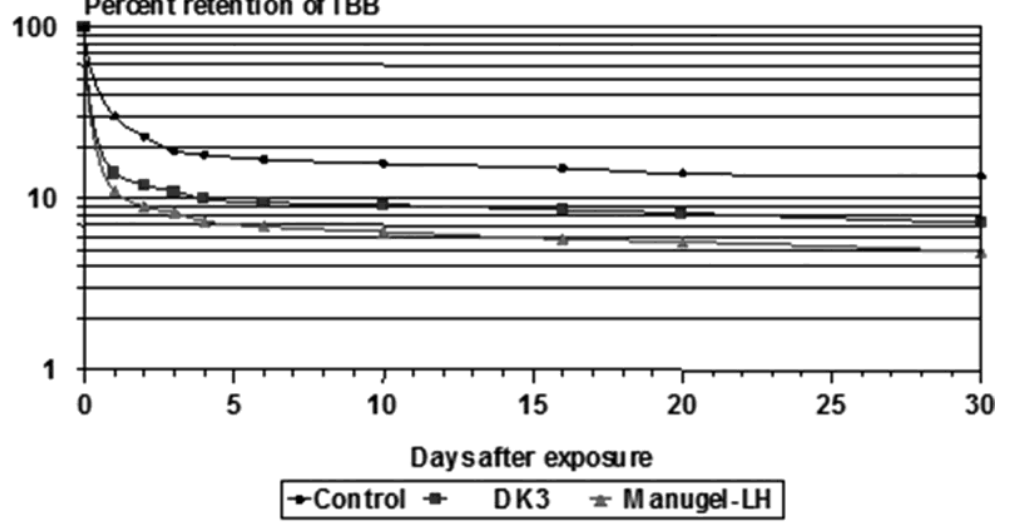

Figure 7. The effect of DK3 and Manugel-LH on the whole body retention of $\mathrm{Sr}-85$ in non-pregnant rats

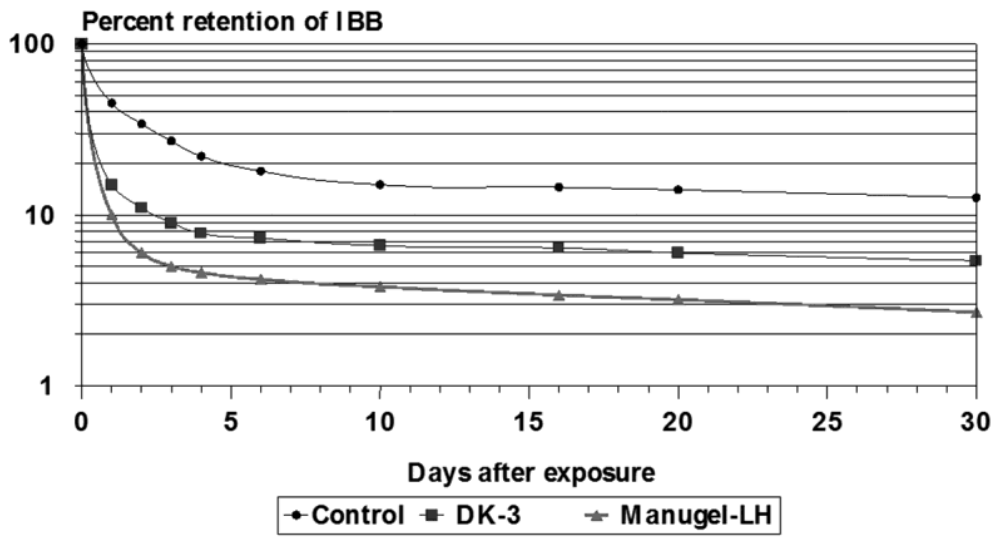

Figure 8. The effect of DK3 and Manugel-LH on the whole body retention of $\mathrm{Sr}-85$ in pregnant rats 


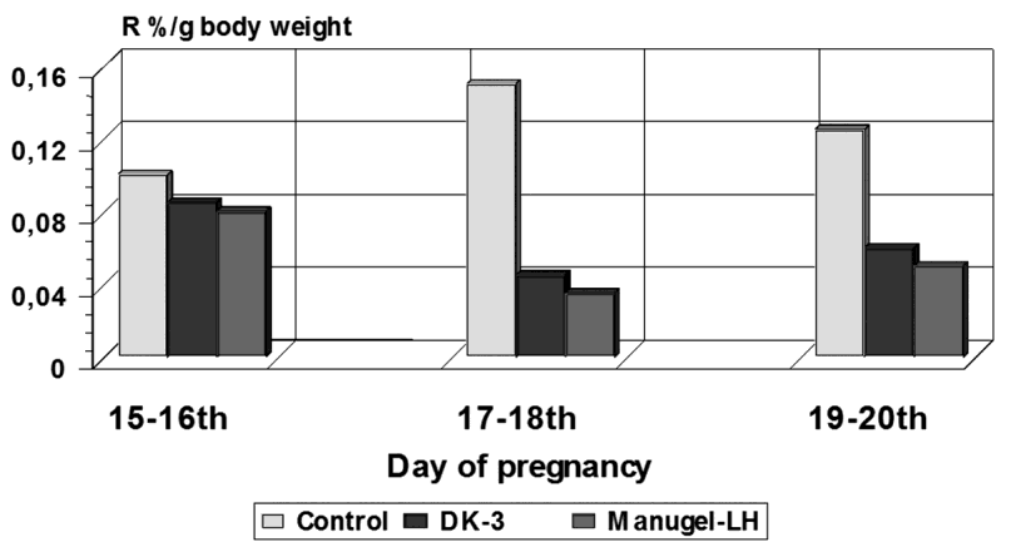

Figure 9. Sr-85 intake/gram body weight of new-born rats as a percentage mother's initial body burden (IBB)

3.) Effect of decorporating agents (DK-1, DTPA) on the whole body retention of $\mathrm{Ce}-144$ in rats:

In nuclear reactions, primarily in fission products occurring during nuclear weapon tests the $\mathrm{Ce}-144$ is present in 4.6-6.2\%. This isotope has a significant rate in radiation hygiene, being a potential environmental pollutant as a byproduct of nuclear industry/reactions.

The values for whole body retention of the radioisotopes in control and treated rats are shown in the Figure 10.

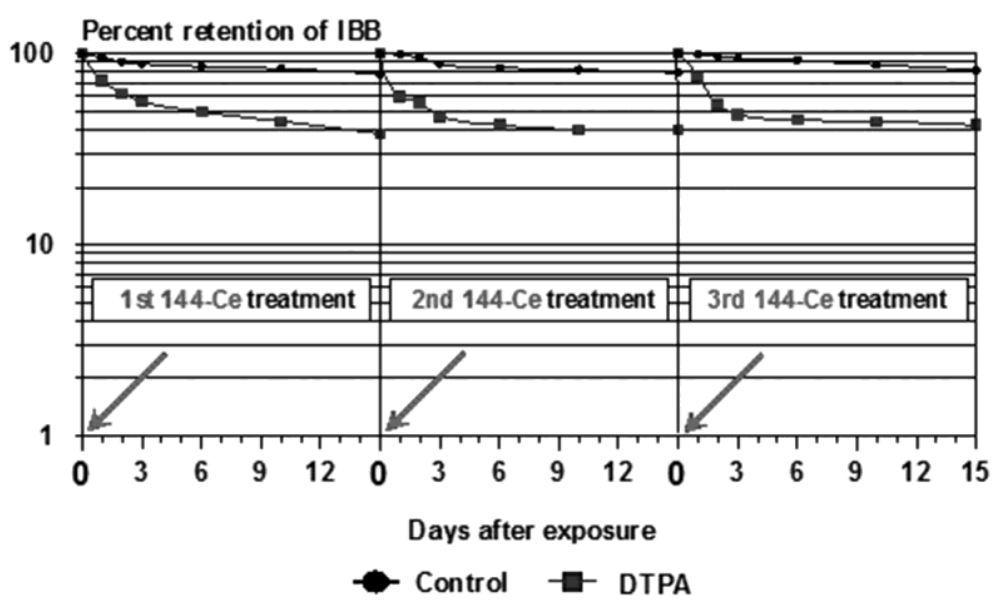

Figure 10. Effect of DTPA (DK-1) treatment on the whole body retention of Ce-144 after repeated exposure

From the results (in control group) it can be stated that the long-life components belong- ing to the various retention curves indicated an increase (e.g. at the end of $3^{\text {rd }}$ period about

1.2-2.5 times) in the deposition of radioisotope after repeated exposures, consequently the rate of elimination decreased. But treatments applied DTPA (DK-1) caused a significant decrease (about 50-80\%) in the retained amount of isotope. [2] [3] [6] 


\section{Conclusions and recommendations}

The results of our animal experiments clearly show that the radioisotopes which in different ways get into the body and there become deposited do significant damage to the whole organ- ism. The degree of damage depends primarily on the type of the isotope (e.g., alpha-, beta- and gamma-radiation), the amount of the isotope (the delivered dose), the route of ingestion (inhalation, ingestion, damage etc.) and the time spent in the organism.

The radioisotopes which have already deposited, practically, cannot be removed by med- ication, nor can the emptying of them be accelerated. Consequently, the effectiveness of the different decorporation methods depend on how quickly the mentioned methods are applied after the contamination. The best results can be achieved with preventive application, if it is not possible then at the soonest possible time after the contamination. The shorter the time is between the contamination and the treatment the better the result is. The possibility of im- mediate or fast treatment can reduce the harmful effects caused by the incorporated isotopes.

Therefore it seems highly recommendable to compile a personal radiological first aid kit, which is necessary for the effective treatment of different exterior and interior contamination caused by the most common fission products, and their mixtures.

For appropriate decorporating (and decontamination) treatments, effective use of a com- plied Personal (self-rescue, emergency) Radiotoxicological (First-Aid) Kit (PRK), which is set for the most important fission products respectively, effective (emergency) treatment of radioisotope inside (and outside) with a mixture of dirt they occurred. [8]

\section{References}

[1] GACHÁLYI A., NAMÉNYI J., SZEGEDI I., VARGA L. P.: Diminution of 85-Sr-retention by adsorbents and radioprotectors in whole-body irradiated rats. Acta biochimica et biophysica; Academiae Scientiarum Hungaricae, 15 (1980), 141-143.

[2] GACHÁLYI A., NAMÉNYI J., SZEGEDI I. VARGA L. P.: Examination of 144-Ce retention in whole-body irradiated mice, treated with complex-forming and radioprotectiv compounds. Acta biochimica et biophysica; Academiae Scientiarum Hungaricae, 16 (1981), 263-268.

[3] GACHÁLYI A., NAMÉNYI J., SZEGEDI I., VARGA L.P.: Modification of 144-Ce tiddue tissue deposition by mixed ligand complex treatment in mice. Acta biochimica et biophysica; Academiae Scientiarum Hungaricae, 68 (1986), $233-240$.

[4] NAMÉNYI J., GACHÁLYI A., VARGA, L. P.: Decorporation of 85-Sr by radioadsorbents from the lung of rats with bronchial disorders. Health Physics, 51 (1986) 539-544.

[5] GACHÁLYI A., NAMÉNYI J., SZEGEDI I., VARGA L. P.: Mobilization of 85- Sr by flavone derivatives (Morin and Ipriflavone) in normal and pregnant rats. Radiobiology and Radiotherapy, 29 (1988), 513-517.

[6] GACHÁlYI A., NAMÉNYI J., SZEGEDI I., VARGA L. P.: Effect of mixed ligand complex therapy on the retention of 95$\mathrm{Nb}$ and 144-Ce in mice. Radiation Research, 120 (1989), 177-181. DOI: https://doi.org/10.2307/3577644 
GACHÁLYI András, GYULAI Gábor: Effects of different decorporating agents...

[7] GACHÁLYI A., NAMÉNYI J., SZEGEDI I. (1991): Mobilization of Cs-134 by colloidal Prussian blue in normal and pregnant rats. In. Radiation Research Congress Abstract Vol.1. PO3, 25SP Academic Press. DOI: https://doi.org/10.1016/B978-0-12-168561-4.50543-6

[8] GYULAI G., FÜRÉSZ J., GACHÁLYI A., NAMÉNYI J. (2001): Effect of different decorporating agents on the whole body retention of radioisotopes Dubrovnik. IRPA Regional Congress on Radiation Protection in Central Europe, Abstract: Proceedings ISBN 9539613337 